\title{
Analyzing an UWB Bandpass Filter for High Power Applications Using Rectangular Coaxial Cables with Square Inner Conductors
}

\author{
Nasreddine Benahmed ${ }^{1}$, Nadia Benabdallah ${ }^{2}$, Salima Seghier $^{3}$, Fethi Tarik Bendimerad ${ }^{1}$, \\ Boumedienne Benyoucef ${ }^{1}$ \\ ${ }^{1}$ University Abou Bekr Belkaid-Tlemcen, Tlemcen, Algeria \\ ${ }^{2}$ Preparatory School of Sciences and Technology (EPST-Tlemcen), Tlemcen, Algeria \\ ${ }^{3}$ University of Saida, Saida, Algeria \\ E-mail: N_Benahmed@yahoo.fr \\ Received February 5, 2011; revised April 6, 2011; accepted April 13, 2011
}

\begin{abstract}
Using the finite element method (FEM) in two dimensions and the CST MICROWAVE STUDIO ${ }^{\circledR}$ (CST MWS) Transient Solver, the electromagnetic (EM) analysis and the design of a novel compact ultra wideband (UWB) bandpass filter using rectangular coaxial cables with square inner conductors, convenient for high power applications, are presented. The design of the UWB BP filter is based on the use of impedance steps and coupled-line sections. The center frequency around $6.85 \mathrm{GHz}$ was selected, the bandwidth is between $3-10 \mathrm{GHz}$, the insertion-loss amounts to around $0.35 \mathrm{~dB}$ and the return loss is found higher than 10 $\mathrm{dB}$ in a large frequency range $4-9.5 \mathrm{GHz}$. The simulated results of stopband performances are better than 15 $\mathrm{dB}$ for a frequency range up to $11 \mathrm{GHz}$. For the selected center frequency and on a substrate with a dielectric constant of 2.03, the rectangular coaxial cables BPF with square inner conductors is only $6.7 \times 8.9 \times 33.4$ $\mathrm{mm}$ in size.
\end{abstract}

Keywords: Rectangular Coaxial Cables, Square Inner Conductors, Ultra Wideband Bandpass Filter, Compact Filter, Electromagnetic Parameters, Analysis and Design, FEM Method, CST MWS Transient Solver

\section{Introduction}

Since the Federal Communications Commission (FCC) released the unlicensed use of ultra-wideband (UWB: 3.1 to $10.6 \mathrm{GHz}$ ) wireless systems in February 2002 [1], many researchers have started exploring various UWB components, devices, and systems [2,3]. As one of the key circuit blocks in the whole system, the UWB bandpass filter (BPF) has been studied through the use of the matured filter theory [4] and other techniques $[5,6]$.

On the basis of impedance steps and coupled-line sections as inverter circuits, several works were interested in the design of planar broadband filters with low loss, compact size, high suppression of spurious responses, and improved stopband performances [7,8].

In this work, we propose a novel and a simple compact ultra wideband (UWB) bandpass filter using rectangular coaxial cables with square inner conductors, convenient for high power applications. The filter can be easily designed and fabricated using FeeFEM environment [9], CST MICROWAVE STUDIO ${ }^{\circledR}$ (CST MWS) Transient Solver [10] or other commercial EM software. The design of the UWB filter is based on the use of impedance steps and coupled-line sections. The center frequency around $6.85 \mathrm{GHz}$ was selected, the bandwidth is between $3-10 \mathrm{GHz}$, the insertion-loss amounts to around $0.35 \mathrm{~dB}$ and the return loss is found higher than $10 \mathrm{~dB}$ in a large frequency range $(4-9.5) \mathrm{GHz}$. The simulated results of stopband performances are better than $15 \mathrm{~dB}$ for a frequency range up to $11 \mathrm{GHz}$. For the selected center frequency and on a substrate with a dielectric constant of 2.03 , the rectangular coaxial cable BPF with square inner conductors is only $6.7 \times 8.9 \times 33.4 \mathrm{~mm}$ in size. What follows are the analysis and the design of this compact UWB filter using both FEM method under FeeFEM environment and CST MWS Transient Solver. 


\section{Rectangular Coaxial Cables}

Coupled rectangular coaxial cables can provide signal coupling in a compact form for any characteristic impedance systems. They were used previously in [11] to build a directional coupler. This kind of coupler has excellent performance in terms of high directivity, low VSWR, good isolation, excellent electromagnetic interference (EMI) shielding, high power handling capability, and low cost due to the use of commercial semirigid rectangular coaxial cables and elimination of a mechanical housing.

Figure 1 shows the cross-section of a rectangular coaxial coupled line with square inner conductors. The cable is assumed to be lossless with an inner squared conductor of side $\left(2 a_{1}\right)$ and an outer rectangular conductor of height $\left(2 a_{2}\right)$ and width $\left(2\left(a_{2}+h\right)\right)$. Dielectric material with dielectric constant $\left(\varepsilon_{\mathrm{r}}\right)$ fills the inside of the cable. A portion of each cable is cut out and two of these cut cables are joined to form the coupled line. The cut depth is represented by $(h)$ on the cross section as shown in Figure 1.

\section{Numerical Resolution}

The electrical properties of the lossless and homogeneous symmetrical coupler presented in Figure 1 can be described in terms of its primary parameters $[L]$ and $[C]$, and its secondary parameters $k, Z_{0 e}$ and $Z_{0 o}[12,13]$.

where: $\quad[L]=\left[\begin{array}{cc}L_{11} & L_{12} \\ L_{21} & L_{22}\end{array}\right] ;[C]=\left[\begin{array}{ll}C_{11} & C_{12} \\ C_{21} & C_{22}\end{array}\right]$

The inductance matrix $[L]$ contains the self-inductances on the diagonal $\left(L_{11}=L_{22}\right.$ are the proper inductances) and the mutual inductances $\left(L_{12}=L_{21}\right)$ between the two coupled lines.

Matrix [C] accounts for the capacitative effects between the two coupled lines, characterizing the electric field energy storage in the coupler. $\left(C_{11}=C_{22}\right)$ are the proper capacitances and $\left(C_{12}=C_{21}\right)$ is the coupling capacitance.

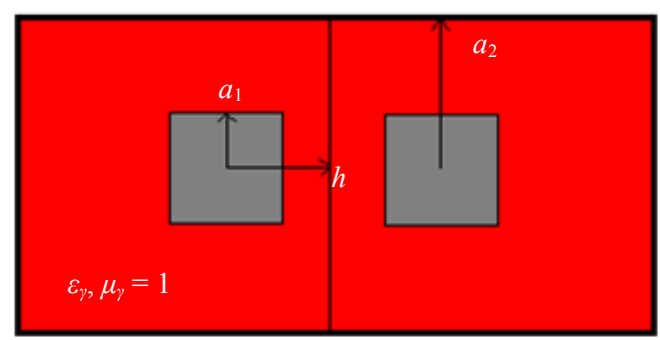

Figure 1. Cross section of the rectangular coaxial coupled line with square inner conductors.

$$
k=\frac{L_{12}}{L_{11}}=\frac{C_{12}}{C_{11}} ;
$$

is the coupling coefficient and $\left(Z_{0 e}, Z_{0 o}\right)$ are respectively the even- and the odd-modes characteristic impedances of the coupler.

On the other hand, the isolated line of Figure 2 is described in terms of its inductance and capacitance per unit length ( $L$ and $C$ ) and in term of its characteristic impedance $Z_{0}$.

In reference 14 , we successfully realized a numerical tool under FreeFEM environment, used to analyze electromagnetic (EM) parameters for rectangular coaxial couplers with square inner conductors. This numerical tool can be easily adapted to study any other TEM or quasi-TEM structure [15]. Also, we proposed rigorous analytical expressions for the primary parameters (inductance $[\mathrm{L}]$ and capacitance $[C]$ matrices) and the impedances $\left(Z_{0 e}, Z_{0 o}\right)$ of the even- and odd-modes for rectangular coaxial couplers with square inner conductors [14]. The analytical expressions are convenient for all coupled rectangular coaxial couplers having square inner conductors with a wide range of cut depths and an outer to inner conductor ratio between 1.4 and 10 . We proposed others analytical expressions in order to calculate the EM parameters of squared coaxial lines [16]. All our analytical expressions were deduced from rigorous analyses by the FEM and MoM methods under respecttively FreeFEM and LINPAR [17] environments. Using these analytical expressions, an analysis can be readily implemented in modern CAE software tools for the design of microwave and wireless components.

\section{UWB Filter Using Rectangular Coaxial Cables}

Assuming 50- $\Omega$ external feeding lines, Figures 3(a) and 3(b) show respectively the $3 \mathrm{D}$ schematic representation and the longitudinal section of the proposed UWB BPF. An isolated rectangular coaxial line with one square inner conductor in the middle and a rectangular coaxial coupled line with square inner conductors at the two ends [18].

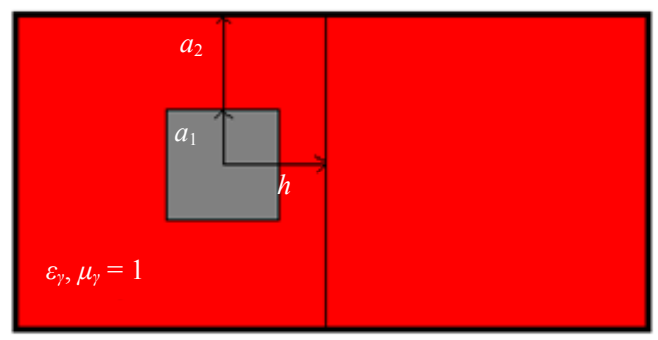

Figure 2. Cross section of the rectangular coaxial line with one square inner conductor. 
To achieve the specified UWB bandpass, the three sections of this filter are arranged with the lengths of about one quarter-, one half-, and one quarter-wavelength, i.e., $\lambda / 4, \lambda / 2$ and $\lambda / 4$ [18], as marked in Figure 3(b).

\section{EM Analyses and Design}

As part of the study, we were interested in the design of the $50 \Omega$-UWB bandpass filter having an inner conductor of side $\left(2 a_{1}=2 \mathrm{~mm}\right)$, an outer conductor of side $\left(2 a_{2}=\right.$ $6.7 \mathrm{~mm}$ ) and a dielectric constant of 2.03 , we have varied the cut depth $(h)$ from $\left(a_{1}\right)$ to $\left(a_{2}\right)$ in order to assure for the rectangular coaxial coupler a coupling coefficient less than $5 \mathrm{~dB}$ (Figure 4).

A coupling coefficient of $2.4 \mathrm{~dB}$ was obtained using our previous works based on FEM for a cut depth $(h)$ of $1.1 \mathrm{~mm}$, yielding a characteristic impedance of approximately $\sqrt{Z_{0 e} \times Z_{0 o}}=26.24 \Omega$ and the following primary EM parameters:

$$
\begin{aligned}
& {[L]=\left[\begin{array}{ll}
190.9 & 144.6 \\
144.6 & 190.9
\end{array}\right]\left(\frac{n H}{m}\right)} \\
& {[C]=\left[\begin{array}{ll}
278.7 & -211.4 \\
-211.4 & 278.7
\end{array}\right]\left(\frac{p F}{m}\right)}
\end{aligned}
$$

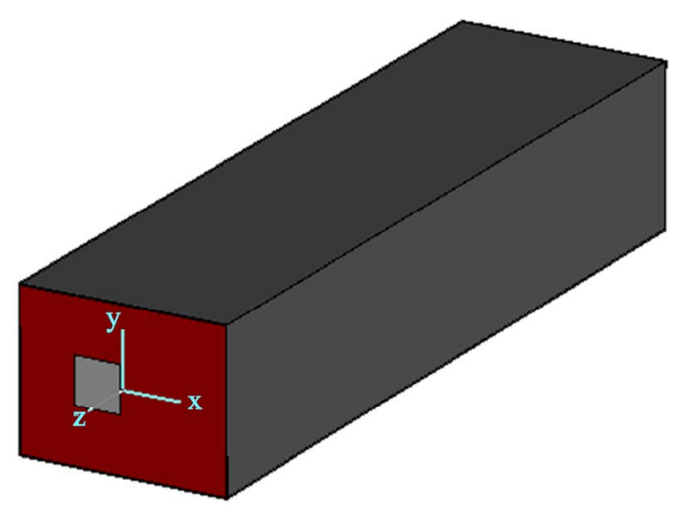

(a)

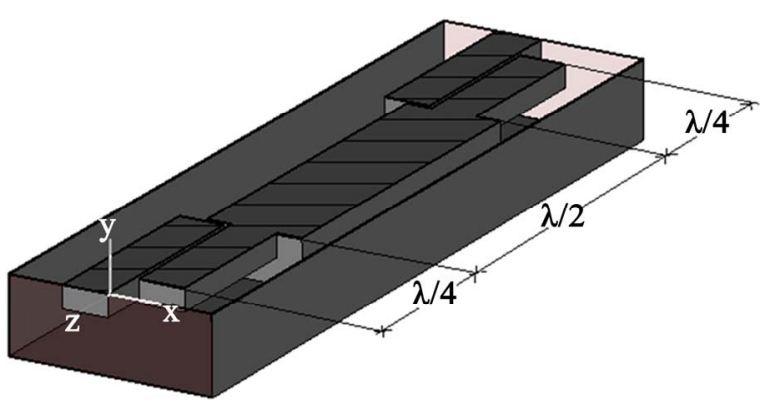

(b)

Figure 3. Longitudinal section of the proposed UWB BPF using rectangular coaxial cables with square inner conductors.
For a length of one quarter-wavelength, i.e., $l=\lambda / 4$ and in order to verify if the designed coupler has a coupling coefficient less than $5 \mathrm{~dB}$ in the frequency range [3.1 - 10.6] GHz, we plotted the resulting coupling coefficient of the rectangular coaxial coupler of Figure 4 versus frequency as shown in Figure 5, using MATPAR software [19]. From this figure, it appears clearly that the coupling coefficient $\left(S_{12}\right)$ and the isolation $\left(S_{14}\right)$ vary respectively between $4-5.5 \mathrm{~dB}$ and $11.4-11.5 \mathrm{~dB}$ in the frequency band [3.1 - 10.6] GHz. In the same frequency band the minimum directivity of the coupler $\left(\left|S_{14}\right|-\left|S_{12}\right|\right)$ is approximately $6 \mathrm{~dB}$.

For the middle line of the UWB BPF represented in Figure 6, the outer conductor parameters, the cut depth (h) and the dielectric constant were kept constants (i.e. $a_{2}$ $=3.35 \mathrm{~mm}, h=1.1 \mathrm{~mm}$ and $\left.\varepsilon_{r}=2.03\right)$ and the inner conductor side $\left(2 a_{1}\right)$ was varied as needed in order to get a characteristic impedance $\left(Z_{0}\right)$ of $19 \Omega$ for the middle line. This value of $\left(Z_{0}\right)$ was obtained for $\left(a_{1}=2.1 \mathrm{~mm}\right)$, yielding an inductance and a capacitance per unit length respectively of $90.75 \mathrm{nH} / \mathrm{m}$ and $248.55 \mathrm{pF} / \mathrm{m}$ [14].

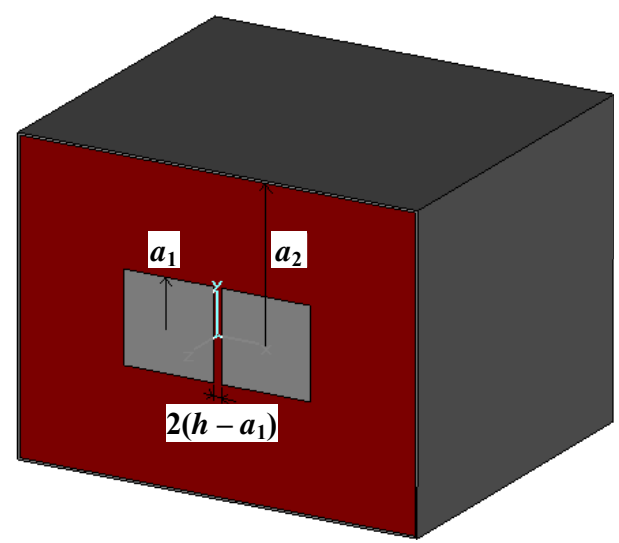

Figure 4. Rectangular coaxial coupler with square inner conductors.

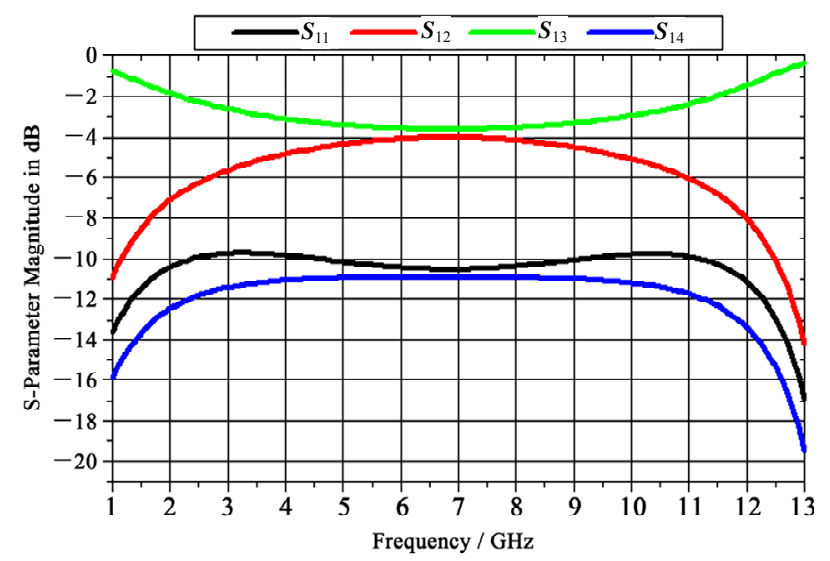

Figure 5. Scattering parameters of the rectangular coaxial coupler presented in Figure 4. 

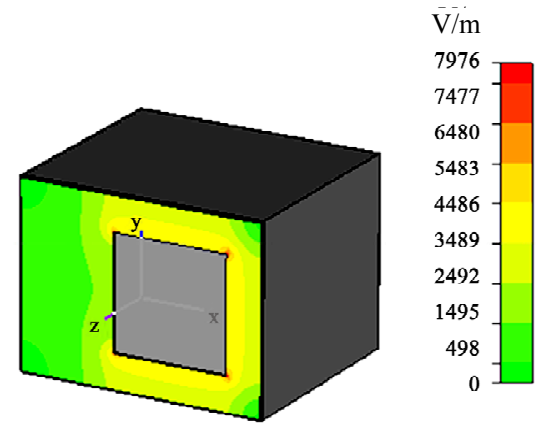

Figure 6. CST simulation of the middle line of the proposed UWB BPF.

We applied the CST MWS Transient Solver in the aim of checking the predicted electrical performance of our proposed and designed UWB BPF using rectangular coaxial cables of Figure 3. The designed filter is characterized by the features marked in Figure 7.

In the frequency range [1 - 11] GHz, Figure 8 provides plots of the resulting scattering parameters obtained of the proposed and designed UWB BPF. It can be seen that the simulated responses, obtained by the CST MWS Transient Solver, of the UWB filter using rectangular coaxial cables with square inner conductors, are in very reasonable agreement with those using planar structures. The plotted wideband also accorded the FCC-defined UWB for high power applications.

For the simulated UWB filter using CST, the insertion-loss amounts to around $0.35 \mathrm{~dB}$ and the return loss is found higher than $10 \mathrm{~dB}$ in a large frequency band (4 9.5) GHz. The simulated results of stopband performances are better than $15 \mathrm{~dB}$ for a frequency range up to $11 \mathrm{GHz}$.

For this type of UWB bandpass filter using rectangular coaxial cables with square inner conductors, there are no numerical or experimental results in the scientific literature. In order to check our results obtained by the CST MWS Transient Solver we were obliged, for the same geometrical and physical parameters of our filter, to make simulations using our previous works and estimate the resulting scattering parameters of the designed UWB filter using MATPAR software. The results coefficients $\left(S_{11}\right)$ and $\left(S_{12}\right)$ as functions of frequency for the proposed UWB BP filter structure are provided in Figure 9. The Figures 8 and 9 show that the responses obtained by the two numerical models (CST and MATPAR) are in a good agreement.

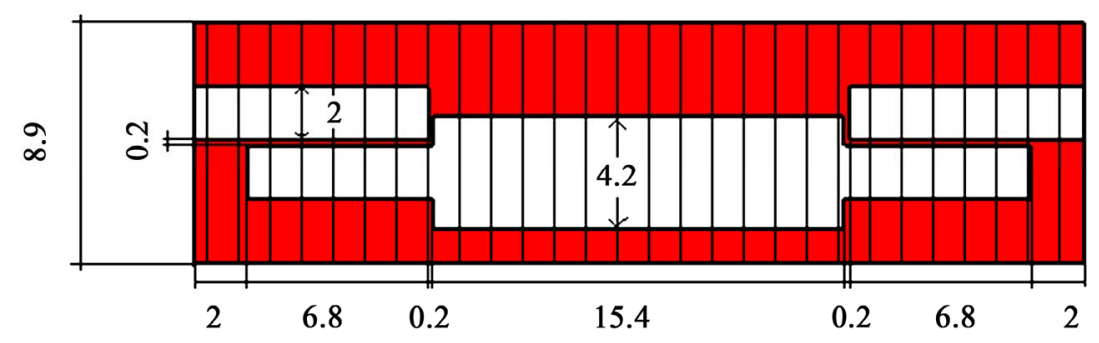

Figure 7. Longitudinal section view of the designed UWB BPF.

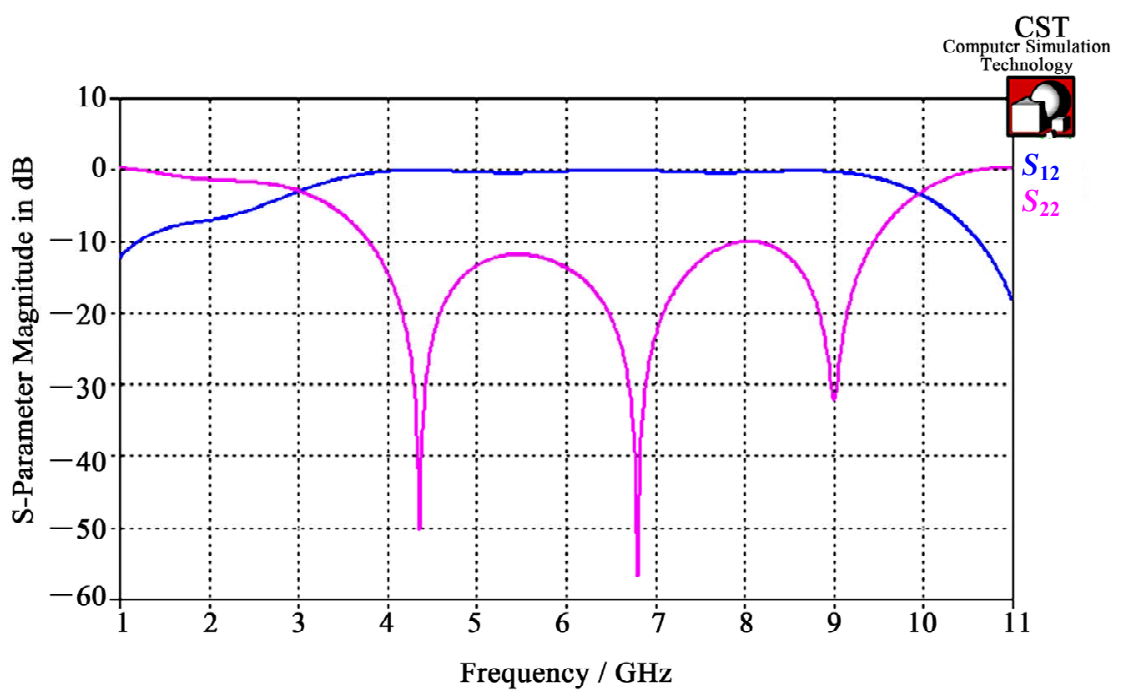

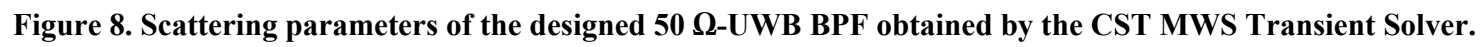




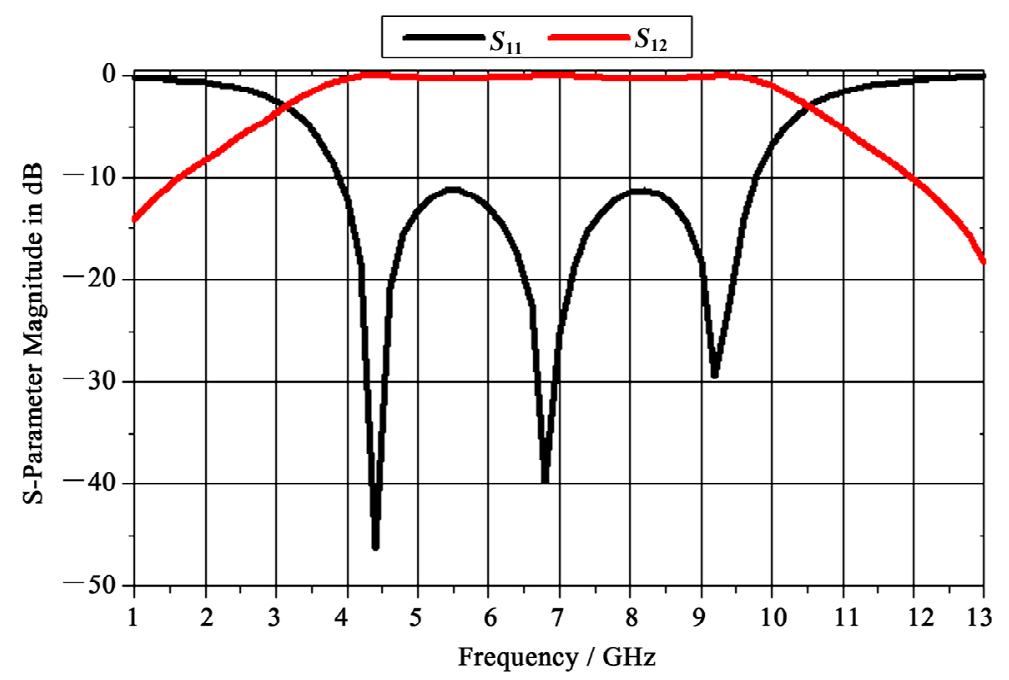

Figure 9. Scattering parameters of the designed $50 \Omega$ UWB BPF obtained by MATPAR software.

\section{Conclusions}

A novel and a simple compact ultra wideband bandpass filter using rectangular coaxial cables with square inner conductors, convenient for high power applications, is presented, analyzed and designed. The design of the UWB filter is based on the use of impedance steps and coupled-line sections.

The designed rectangular coaxial cable bandpass filter is only $6.7 \times 8.9 \times 33.4 \mathrm{~mm}$ in size and can be easily designed and fabricated using CST MICROWAVE STUDIO $^{\circledR}$ Transient Solver or other commercial EM software. The bandwidth of the designed filter is between $3-10 \mathrm{GHz}$, the insertion-loss amounts to around $0.35 \mathrm{~dB}$ and the return loss is higher than $10 \mathrm{~dB}$ in a large frequency range. The simulated results of stopband performances are better than $15 \mathrm{~dB}$ for a frequency range up to $11 \mathrm{GHz}$.

\section{References}

[1] FCC, "Revision of Part 15 of the Commission's Rules Regarding Ultra-Wideband Transmission System," Technical Report ET-Docket 98-153, 14 February 2002.

[2] G. R. Aiello and G. D. Rogerson, "Ultra-Wideband Wireless Systems," IEEE Microwave Magazine, Vol. 4, No. 2, 2003, pp. 36-47. doi:10.1109/MMW.2003.1201597

[3] Z. Irahhauten, H. Nikookar, and G. J. M. Janssen, “An Overview of Ultra Wide Band indoor Channel Measurements and Modeling," IEEE Microwave and Wireless Components Letters, Vol. 14, No. 8, 2004, pp. 386-388. doi:10.1109/LMWC.2004.832620

[4] G. Matthaei, L. Young and E. M. T. Jones, "Design of Microwave Filters, Impedance-Matching Networks, and Coupling Structures," Artech House, Norwood, 1980.

[5] A. Saito, H. Harada and A. Nishikata, "Development of
Bandpass Filter for Ultra Wideband (UWB) Communication Systems," Proceedings of IEEE Conference on Ultra Wideband Systems and Technologies, Reston, 16-19 November 2003, pp. 76-80.

[6] L. Zhu, S. Sun and W. Menzel, "Ultra-Wideband (UWB) Bandpass Filters Using Multiple-Mode Resonator," IEEE Microwave Wireless Components Letters, Vol. 15, No. 11, 2005, pp. 796-798. doi:10.1109/LMWC.2005.859011

[7] J. Gao, L. Zhu, W. Menzel and F. Bögelsack, "Short- Circuited CPW Multiple-Mode Resonator for Ultra-Wideband (UWB) Bandpass Filter," IEEE Microwave Wireless Components Letters, Vol. 16, No. 3, 2006, pp. 104-106. doi:10.1109/LMWC.2006.869870

[8] M. Meeloon, S. Chaimool and P. Akkaraekthalin, "Broadband Bandpass Filters Using Slotted Resonators Fed by Interdigital Coupled Lines for Improved Upper Stopband Performances," International Journal of Electronics and Communications, Vol. 63, No. 6, 2009, pp. 454-463. doi:10.1016/j.aeue.2008.03.005

[9] www.Freefem.org.

[10] www.CST.com.

[11] S. Seghier and N. Benahmed, "Analyse et Conception d'un Coupleur Coaxial Rectangulaire à Conducteurs Internes Circulaires par la Méthode des Eléments Finis," Afrique Science, Vol. 2, No. 3, 2006, pp. 300-313.

[12] N. Benahmed and M. Feham, "Rigorous Analytical Expressions for Electromagnetic Parameters of Transmission Lines: Coupled Sliced Coaxial Cable," Microwave Journal, Vol. 44, No. 11, 2001, pp. 130-138.

[13] N. Benabdallah, N. Benahmed, S. Seghier and R. Bouhmidi, "Sliced Coaxial Cables form Compact Couplers," Microwaves and RF, Vol. 46, No. 7, 2007, pp. 90-94.

[14] N. Benahmed and S. Seghier, "Rigorous Analytical Expressions for the Electromagnetic Parameters of Rectangular Coaxial Couplers with Circular and Square Inner Conductors," Microwave Journal, Vol. 49, No. 8, 2006, pp. 164-174. 
[15] N. Benahmed, M. Feham and M. Kameche, "Finite Element Analysis of Planar Couplers," Applied Microwave \& Wireless, Vol. 12, No. 10, 2000, pp. 28-38.

[16] S. Seghier, N. Benabdallah, N. Benahmed, N. Benmostefa and R. Bouhmidi, "Accurate Closed-Form Formulas for the Electromagnetic Parameters of Squared Coaxial Lines," International Journal of Electronics and Communications, Vol. 62, No. 5, 2008, pp. 395-400.

[17] A. R. Djordjevic, M. B. Bazdar and T. K. Sarkan, "LINPAR for Windows: Matrix Parameters of Multiconductor Transmission Lines, Software and User'S Manual," Artech
House, London, 1999.

[18] W. Menzel, L. Zhu, K. Wu and F. Bogelsack, "On the Design of Novel Compact Broadband Planar Filters," IEEE Transactions on Microwave Theory and Techniques, Vol. 51, No. 2, 2003, pp. 364-370. doi:10.1109/TMTT.2002.807843

[19] A. R. Djordjevic, M. Bazdar, G. Vitosevic, T. Sarkar and R. F. harrington, "Scattering Parameters of Microwave Networks with Multiconductor Transmission Lines," Artech House, London, 1990. 